\title{
Ekuitas Layanan Rawat Inap Rumah Sakit di Indonesia
}

\author{
Equity of Inpatient Utilization in Health Service in Indonesia
}

\author{
Devi Senja Ariani ${ }^{1}$, Pujiyanto ${ }^{2}$ \\ ${ }^{1}$ Pascasarjana IImu Kesehatan Masyarakat, Fakultas Kesehatan Masyarakat, Universitas Indonesia, Depok, Indonesia \\ ${ }^{2}$ Departemen Administrasi dan Kebijakan Kesehatan, Fakultas Kesehatan Masyarakat, Universitas Indonesia, Depok, Indonesia
}

Korespondensi: Devi Senja Ariani

e-mail:devi_senja21@yahoo.com

\begin{abstract}
Abstrak
Dalam rangka mendorong tercapainya UHC di Indonesia, pemerintah menyelenggarakan program Jaminan Kesehatan Nasional (JKN). Salah satu tujuan program JKN adalah perbaikan akses dan ekuitas utilisasi pelayanan kesehatan. Penelitian ini bertujuan untuk menganalisis ekuitas utilisasi layanan rawat inap pada tahun 2015 dan 2016. Penelitian ini menggunakan data sekunder hasil SUSENAS tahun 2015 dan tahun 2016 dengan analisis menggunakan kurva konsentrasi dan indeks konsentrasi. Hasil penelitian menunjukkan bahwa utilisasi layanan rawat inap di rumah sakit pada kelompok peserta JKN meningkat pada tahun 2015 ke tahun 2016. Penduduk kaya lebih banyak memanfaatkan pelayanan rumah sakit dibandingkan dengan penduduk miskin, hal tersebut dibuktikan dengan kurva konsentrasi yang berada dibawah garis diagonal (garis ekuitas) dan nilai indeks konsentrasi yang bernilai positif yaitu 0.0336 pada tahun 2015 dan 0.0382 pada tahun 2016. Terjadi peningkatan inekuitas utilisasi layanan rawat inap di rumah sakit pada tahun 2015 ke tahun 2016 yang dilihat dari selisih nilai indeks konsentrasi sebesar 0.0045. Inekuitas utilisasi layanan rawat inap di rumah sakit yang pro kaya disebabkan oleh ketidaksetaraan umur, pendapatan, pendidikan, wilayah regional tempat tinggal serta kepemilikan JKN. Sedangkan variabel jenis kelamin dan pekerjaan mengurangi inekuitas dalam utilisasi layanan rawat inap di rumah sakit pada tahun 2015 dan 2016.

Kata Kunci: Rawat Inap; Kurva Konsentrasi; Indeks Konsentrasi; Ekuitas: JKN
\end{abstract}

\begin{abstract}
In order to encourage the achievement of UHC in Indonesia, the government organized National Health Insurance (JKN) program. One of the objectives of the JKN program is the improvement of access and equity utilization of health services. This study aims to analyze Equity of Inpatient Utilization in Health Service in second and third year of JKN program implementation in 2015 and 2016. This study uses secondary data of SUSENAS in 2015 and 2016 with analysis using concentration curve and concentration index. The results showed that the Utilization of inpatient services in hospitals in the JKN group of participants increased in 2015 to 2016 . The richer population utilizes more Health Service than the poor, as evidenced by concentration curves below the diagonal line (equity line) and the value of the positive concentration index of 0.0336 in 2015 and 0.0382 in 2016. There was an increase in inequity utilization in inpatient services in 2015 to 2016 which was seen from the difference of concentration index value of 0.0045. Pro-rich inequity caused by inequalities in age, income, education, regional residence and JKN ownership. While sex and job variables reduce inequality in inpatient service utilization in hospital by 2015 and 2016.

Key words: Inpatient, concentration curve, concentration index, equity, JKN, UHC
\end{abstract}

\section{Pendahuluan}

Sistem Jaminan Sosial Nasional (SJSN) diselenggarakan berdasarkan asas kemanusiaan, asas manfaat, dan asas keadilan sosial bagi seluruh rakyat Indonesia (UU Nomor 40 tahun 2004). Prinsip keadilan (ekuitas) juga tertuang dalam UU Nomor 36 Tahun 2009 ditegaskan bahwa setiap orang mempunyai hak yang sama dalam memperoleh akses atas sumber daya di bidang kesehatan dan memperoleh pelayanan kesehatan yang aman, bermutu, dan terjangkau. Oleh karena itu pemerintah wajib untuk memastikan bahwa setiap warga masyarakat dapat memperoleh kemudahan pelayanan kesehatan sesuai dengan prinsip keadilan (ekuitas). Mulai 1 Januari

2014 Pemerintah Indonesia melaksanakan program Jaminan Kesehatan Nasional (JKN). Implementasi program JKN diharapkan dapat memperbaiki akses pelayanan kesehatan bagi masyarakat Indonesia dengan sistem gotong royong sehingga tercapai keadilan (ekuitas).

Data dari profil kesehatan tahun 2016 menunjukkan jumlah Fasilitas Kesehatan Rujukan Tingkat Lanjutan (FKRTL) yang bekerja sama dengan BPJS Kesehatan per 31 Desember 2016 yaitu sebanyak 2.068 FKRTL. Bila dibandingkan dengan tahun 2015, jumlah FKRTL yang bekerja sama dengan BPJS Kesehatan meningkat dari 1.847 
FKRTL pada tahun 2015 menjadi 2.068 FKRTL pada tahun 2016. Peningkatan jumlah FKTP dan FKRTL yang bekerjasama dengan BPJS Kesehatan merupakan salah satu bukti dari besarnya dampak program JKN. Dengan peningkatan jumlah FKTP dan FKRTL tersebut diharapkan peserta JKN dapat memperoleh perbaikan akses pelayanan lebih baik dan lebih berkualitas.

Implementasi tahun pertama JKN berdampak pada peserta PBI yaitu berhasil meningkatkan kemungkinan masyarakat miskin dan dekat penduduk miskin untuk mengakses rawat jalan di fasilitas kesehatan lainnya (Rolindrawan, 2015). Selain itu JKN juga meningkatkan akses layanan rawat inap sebesar 115,8\% dan terbukti mampu mempersempit kesenjangan layanan rawat inap dirumah sakit (Nugraheni, 2017). Kepemilikan jaminan kesehatan memberikan proteksi finansial yang diakibatkan pengeluaran biaya kesehatan, khususnya pengeluaran biaya katastropik jika dibandingkan dengan yang tidak memiliki jaminan kesehatan (Tarigan, 2017).

Berbeda dengan hasil penelitian Oktavianti (2017) yang menunjukkan bahwa penduduk kaya di Indonesia lebih banyak memanfaatkan pelayanan rumah sakit dibandingkan dengan penduduk miskin. Ketidakmerataan utilisasi rawat jalan dan rawat inap yang pro-kaya disebabkan oleh ketidaksetaraan umur, jenis kelamin, geografis, pernikahan, pendidikan dan pengeluaran. Di China, penelitian Flato dan Zhang (2016) menunjukkan inequity (ketidakseimbangan) pro-kaya dalam tingkat utilisasi layanan kesehatan meningkat setelah adanya kebijakan UHC (Universal Health Coverage). Pengguna yang lebih kaya lebih mungkin untuk mencari perawatan di rumah sakit daripada di klinik atau pusat kesehatan. Penelitian Nadjib (1999) menjelaskan bahwa sarana pelayanan kesehatan, letak geografis dan pengeluaran per kapita merupakan faktor yang penting dalam mewujudkan ekuitas dalam pelayanan kesehatan. Apabila salah satu tidak merata maka akan menyebabkan inekuitas pelayanan kesehatan.

Hasil temuan yang beragam menunjukkan bahwa masalah ekuitas terhadap utilisasi pelayanan kesehatan menjadi isu penting yang menggambarkan kesenjangan yang terjadi dalam mengakses pelayanan kesehatan. Perbedaan faktor sosial ekonomi, asuransi kesehatan, kebutuhan kesehatan dan geografis mempengaruhi utilisasi dalam pelayanan kesehatan. Ketimpangan pelayanan kesehatan di Indonesia diharapkan dapat diperbaiki melalui pelaksanaan program JKN. Oleh karena itu, penelitian ekuitas utilisasi layanan kesehatan merupakan hal yang penting dilakukan dalam rangka monitoring dan evaluasi pelaksanaan kebijakan JKN untuk memperoleh gambaran apakah terdapat perbaikan ekuitas utilisasi layanan rawat inap pada tahun kedua dan ketiga implementasi program JKN yaitu pada tahun 2015 dan tahun 2016 dan sebagai bahan masukan bagi rekomendasi kebijakan pemerintah.

\section{Metodologi Penelitian}

Penelitian ini menggunakan desain studi repeated cross sectional. Penelitian menggunakan data sekunder dari hasil Survei Ekonomi Nasional (SUSENAS) tahun 2015 dan tahun 2016 yang berasal dari Badan Pusat Statistik (BPS). Data yang digunakan yaitu gabungan dari kuesioner keterangan pokok rumah tangga (kuesioner kor) dan kuesioner keterangan konsumsi dan pengeluaran rumah tangga tahun 2015 dan 2016. Kode Kuesioner kor yang digunakan adalah kode VSEN14.K untuk tahun 2015 dan VSEN16.K untuk tahun 2016. Sedangkan untuk kuesioner konsumsi dan pengeluaran rumah tangga, memiliki kode VSEN14.M untuk tahun 2015 dan VSEN16.KP untuk tahun 2016.

Data susenas yang digunakan sebagai variabel dalam penelitian ini adalah umur, jenis kelamin, lokasi tempat tinggal, wilayah regional, status pernikahan, pendidikan, pekerjaan, pendapatan per kapita yang merupakan proksi dari pengeluran rumah tangga, kepemilikan jaminan kesehatan dan variabel utilisasi rawat inap di rumah sakit. Populasi dalam penelitian ini adalah seluruh sampel individu yang merupakan responden dari Susenas tahun 2015 dan tahun 2016 yang tersebar di 34 provinsi di Indonesia.

Penelitian ini merujuk pada ekuitas horizontal yaitu orang dengan kebutuhan kesehatan yang sama harus mendapatkan pelayanan kesehatan yang sama tanpa melihat status sosial ekonomi mereka. Kebutuhan yang sama ini diproksi dari status kesehatan, yaitu mereka yang sakit atau mengalami keluhan kesehatan dan dirawat dirumah sakit. Sehingga kriteria inklusi sampel dalam penelitian ini adalah responden yang sakit atau mengalami keluhan kesehatan dan melakukan pengobatan rawat inap dirumah sakit swasta dan rumah sakit pemerintah tahun 2015 dan tahun 2016.

Kriteria eksklusi dalam penelitian ini adalah responden yang menjawab memiliki jaminan kesehatan BPJS Ketenagakerjaan, Jaminan Kesehatan dari asuransi swasta dan jaminan kesehatan dari 
Perusahaan/Kantor serta responden yang memiliki dua jaminan kesehatan (double insurance). Unit analisis dalam penelitian ini adalah individu. Total sampel responden yang dikumpulkan oleh Badan Pusat Statistik (BPS) yaitu 1.097.719 individu pada tahun 2015 dan 1.109.749 individu pada tahun 2016. Jumlah sampel penelitian setelah dilakukan inklusi dan ekslusi adalah 17.421 individu pada tahun 2015 dan 18.053 individu pada tahun 2016 .

Dalam penelitian ini pengukuran ekuitas dilakukan dengan menggunakan kurva konsentrasi dan indeks konsentrasi. Kurva konsentrasi dapat digunakan untuk mengukur kesenjangan atau inekuitas tidak hanya pada outcome kesehatan tapi juga dapat digunakan untuk mengukur perbedaan dalam kesenjangan kesehatan (O’Donnell et. al, 2008). Kurva konsentrasi menggambarkan proporsi kumulatif utilisasi layanan rawat inap di rumah sakit pada proporsi kumulatif penduduk yang dirangking menurut pendapatan per kapita dari yang terendah hingga tertinggi. Jika kurva konsentrasi menempel pada garis diagonal (garis ekuitas), maka telah terjadi ekuitas dalam memperoleh akses pelayanan kesehatan. Semakin jauh kurva berada di atas garis diagonal, semakin terkonsentrasi variabel kesehatan di antara orang miskin. Sebaliknya, semakin jauh kurva berada di bawah garis dari kesetaraan, semakin terkonsentrasi variabel kesehatan di antara orang kaya. Namun kurva konsentrasi tidak memberikan ukuran besarnya ketimpangan yang dapat dibandingkan, oleh karena itu, analisis akan dilanjutkan dengan menghitung indeks konsentrasi. Indeks konsentrasi memiliki nilai antara -1 dan 1 dengan rumus perhitungan sebagai berikut (O’Donnel et al, 2008):

$$
C=\frac{2}{\mu} \operatorname{cov}(h, r)
$$

Dimana $h$ adalah utilisasi layanan rawat inap di rumah sakit, $\mu$ adalah nilai tengah dari $h$ dan $r$ merupakan peringkat distribusi tingkat pendapatan per kapita masyarakat. Indeks konsentrasi juga dapat dihitung melalui regresi Ordinary Least Square (OLS) (Kakwani et al, 1997 dalam O’Donnel et al, 2008) yang di rumuskan sebagai berikut:

$$
2 \sigma_{r}^{2}\left(\frac{h_{t}}{\mu}\right)=\alpha+\beta r_{i}+\varepsilon_{t}
$$

Dimana $\sigma_{r}^{2}$ adalah variasi tingkat utilisasi pada $r$ kelompok pendapatan. Estimasi $\beta$ pada regresi OLS adalah estimasi indeks konsentrasi yang ekuivalen dengan persamaan sebelumnya. Dalam regresi linier syarat yang harus dipenuhi agar taksiran parameter model tersebut bersifat BLUE (Best, Linear, Unbiased and Estimator) adalah varians konstan (homoskedastisitas) dan tidak ada korelasi antara error term (autokorelasi). Nilai negatif menunjukkan bahwa utilisasi rawat inap rumah sakit lebih condong kepada masyarakat miskin dengan letak kuva konsentrasi diatas garis ekuitas, dan sebaliknya. Jika indeks konsentrasi bernilai positif berarti variabel kesehatan yang diukur mengarah ke masyarakat mampu dengan letak kurva konsentrasi dibawah garis ekuitas. Jika tidak terjadi ketimpangan maka nilai indeks konsentrasi adalah nol (Kakwani et al, 1997).

Untuk menganalisis kontribusi berbagai faktor penentu terhadap inekuitas/ketidaksetaraan utilisasi layanan rawat inap analisis dilanjutkan dengan dekomposisi Indeks konsentrasi. Wagstaff, et.al (2003) menjelaskan bahwa dekomposisi indeks konsentrasi adalah cara mudah untuk menguraikan mengukur tingkat inekuitas dengan kontribusi dari berbagai faktor penjelas. Menurut metode ini, indeks konsentrasi pemanfaatan rawat inap bisa didekomposisi menjadi empat komponen : (1) pendapatan perorangan, (2) variabel kebutuhan, seperti keluhan kesehatan penyakit kronis dan akut, (3) penjelasan lainnya variabel, termasuk asuransi kesehatan, tingkat pendidikan, pekerjaan, dll, dan (4) istilah residual, yang mencerminkan ketidaksetaraan yang tidak bisa dijelaskan dengan variasi sistematis kelompok pendapatan di variabel lain. Model regresi yang digunakan adalah sebagai berikut (O'Donnel et al, 2008):

$$
Y_{i} Y_{i}=\propto+\Sigma_{k} \beta_{k} X_{k i}+\varepsilon_{i} \propto+\Sigma_{k} \beta_{k} X_{k i}+\varepsilon_{i}
$$

Dimana $y_{i}$ adalah utilisasi rawat inap di rumah sakit, $\alpha$ adalah intercept, $X_{\mathrm{ki}}$ adalah kontribusi relative dari determinan, $\epsilon_{i}$ merupakan error term. Dan indeks konsentrasi untuk Y, C, dapat dituliskan sebagai berikut:

$$
\mathrm{C}=\sum_{k}\left(\beta_{k} \bar{x}_{k} / \mu\right) C_{k}+G C_{\varepsilon} / \mu
$$

Dimana, $\mathrm{C}_{\mathrm{k}}$ adalah indeks konsentrasi untuk $X_{\mathrm{ki}}, \beta_{\mathrm{k}}$ 
adalah koefisien regresi utilisasi rawat inap pada determinan $\mathrm{k}, \mathrm{X}_{\mathrm{k}}$ adalah mean dari $X_{\mathrm{ki}}, \mu$ adalah mean dari $y_{i} \cdot \mathrm{GC}_{\epsilon}$ adalah indeks konsentrasi untuk error term.

\section{Hasil Penelitian}

\section{Utilisasi Layanan Rawat Inap di Rumah Sakit}

Tabel 1 menunjukkan bahwa terjadi peningkatkan utilisasi layanan rawat inap di rumah sakit pada tahun 2015 dan 2016. Responden lebih banyak memanfaatkan layanan rawat inap di rumah sakit milik pemerintah daripada dirumah sakit swasta. Jika dibandingkan dengan tahun 2015, pada tahun 2016 terjadi kenaikan utilisasi layanan rawat inap pada kelompok peserta JKN yaitu sebesar 21,2\% pada utilisasi di RS Swasta dan 52,1\% pada utilisasi di RS Pemerintah.

Tabel 1. Utilisasi Layanan Rawat Inap di Rumah Sakit berdasarkan Kepemilikan Jaminan Kesehatan

\begin{tabular}{lcccc}
\hline \multirow{2}{*}{ Jenis RS } & \multicolumn{2}{c}{ Tahun 2015} & \multicolumn{2}{c}{ Tahun 2016} \\
\cline { 2 - 5 } RS Swasta & $\mathrm{N}$ & $\%$ & $\mathrm{~N}$ & $\%$ \\
-JKN & $\mathbf{5 , 6 6 0}$ & $\mathbf{3 2 . 5}$ & $\mathbf{5 , 7 7 9}$ & $\mathbf{3 2 . 0}$ \\
-Tidak ada & 3,468 & 19.9 & 3,834 & 21.2 \\
Jaminan & 2,192 & 12.6 & 1,945 & 10.8 \\
& & & & \\
RS Pemerintah & $\mathbf{1 1 , 5 1 2}$ & $\mathbf{6 6}$ & $\mathbf{1 2 , 0 3 4}$ & $\mathbf{6 6 . 7}$ \\
-JKN & 8,980 & 51.5 & 9,408 & 52.1 \\
-Tidak ada & 2,532 & 14.5 & 2,626 & 14.5 \\
Jaminan & & & & \\
RS Swasta \& & $\mathbf{2 4 9}$ & $\mathbf{1 . 4}$ & $\mathbf{2 4 0}$ & $\mathbf{1 . 3}$ \\
Pemerintah & 191 & 1.1 & 189 & 1.0 \\
-JKN & 58 & 0.3 & 51 & 0.3 \\
-Tidak ada & $\mathbf{7 2 1}$ & $\mathbf{1 0 0}$ & $\mathbf{1 8 , 0 5 3}$ & $\mathbf{1 0 0}$ \\
\hline Jaminan & & & & \\
Total & &
\end{tabular}

Ekuitas Utilisasi Layanan Rawat Inap di Rumah Sakit

Ekuitas layanan rawat inap dalam penelitian ini dianalisis dengan menggunakan kurva konsentrasi dan indeks konsentrasi. Kurva konsentrasi memberikan gambaran proporsi kumulatif utilisasi layanan rawat inap di rumah sakit pada proporsi kumulatif penduduk yang dirangking menurut pendapatan per kapira dari yang terendah hingga tertinggi.

Kurva konsentrasi antara tahun 2015 dan 2016 menunjukkan fenomena yang hampir sama yakni mendekati garis ekuitas atau garis diagonal dan saling berhimpitan (Gambar 1) artinya terjadi ketimpangan (inekuitas) terhadap utilisasi layanan rawat inap di rumah sakit selama program JKN berlangsung pada tahun kedua dan ketiga, namun ketimpangan tersebut sangat kecil. Letak kurva dibawah garis ekuitas menunjukkan bahwa utilisasi rawat inap di rumah sakit lebih banyak digunakan oleh kelompok kaya.

Nilai indeks konsentrasi layanan rawat inap meningkat antara tahun 2015 ke tahun 2016 yaitu sebesar 0.0045 (Tabel 2). Besarnya nilai indeks konsentrasi pada kedua tahun tersebut sangat kecil, artinya ketimpangan (inekuitas) terhadap utilisasi layanan rawat inap di rumah sakit sangat kecil selama pelaksanaan program JKN di tahun kedua dan ketiga. Nilai positif indeks konsentrasi pada tahun 2015 dan 2016 menunjukkan bahwa utilisasi layanan rawat inap lebih banyak digunakan oleh kelompok kaya (pro rich).

\begin{tabular}{|c|c|c|c|c|}
\hline \multicolumn{5}{|c|}{$\begin{array}{c}\text { Tabel } 2 \text { Indeks Konsentrasi Layanan Rawat Inap } \\
\text { Rumah Sakit Tahun } 2015 \text { dan Tahun } 2016\end{array}$} \\
\hline \multicolumn{2}{|c|}{2015} & \multicolumn{2}{|c|}{2016} & \multirow{2}{*}{$\begin{array}{l}\text { Selisih } \\
\text { CI }\end{array}$} \\
\hline $\mathrm{CI}$ & Std. Err. & $\mathrm{CI}$ & $\begin{array}{l}\text { Std. } \\
\text { Err. }\end{array}$ & \\
\hline 0.0336 & 0.0073 & 0.0382 & 0.0110 & 0.0045 \\
\hline
\end{tabular}

Gambar 2 menggambarkan ekuitas layanan rawat inap berdasarkan kepemilikan jaminan kesehatan yaitu tidak memiliki jaminan dan memiliki JKN. Pada tahun 2015 kurva konsentrasi untuk kelompok JKN lebih dekat dengan garis diagonal dibandingkan pada kelompok yang tidak memiliki jaminan. Hal tersebut menunjukkan bahwa pada tahun 2015 ekuitas utilisasi layanan rawat inap pada peserta JKN cenderung lebih baik dibandingkan pada kelompok yang tidak memiliki jaminan kesehatan (gambar 2). Sedangkan pada tahun 2016 kurva konsentrasi menunjukkan hal yang berbeda dibandingkan tahun 2015.

Pada tahun 2016 gambar kurva konsentrasi pada kelompok JKN dan kelompok yang tidak memiliki jaminan terlihat saling berhimpitan, kelompok JKN terlihat mengalami pergeseran sedikit menjauhi garis diagonal/garis ekuitas, artinya terjadi peningkatan ketimpangan (inekuitas) dalam utilisasi layanan rawat inap pada tahun 2016. Kurva konsentrasi berada dibawah garis diagonal artinya pemanfaatan layanan rawat inap lebih banyak dilakukan oleh orang kaya. 
Gambar 1 Kurva Konsentrasi Layanan Rawat Inap di Rumah Sakit Tahun 2015 dan Tahun 2016

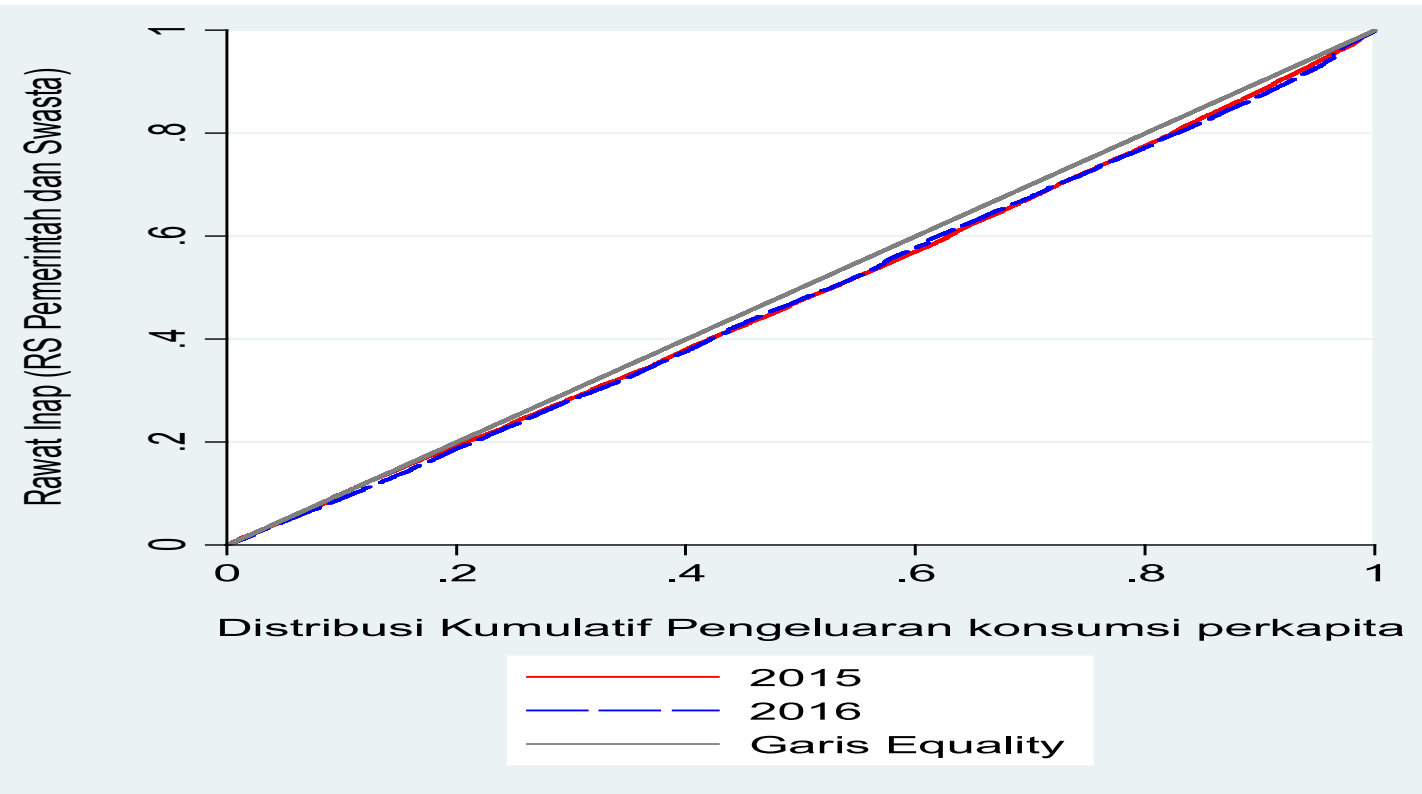

Gambar 2 Kurva Konsentrasi Layanan Rawat Inap di Rumah Sakit Berdasarkan Kepemilikan Jaminan Kesehatan Tahun 2015 dan Tahun 2016

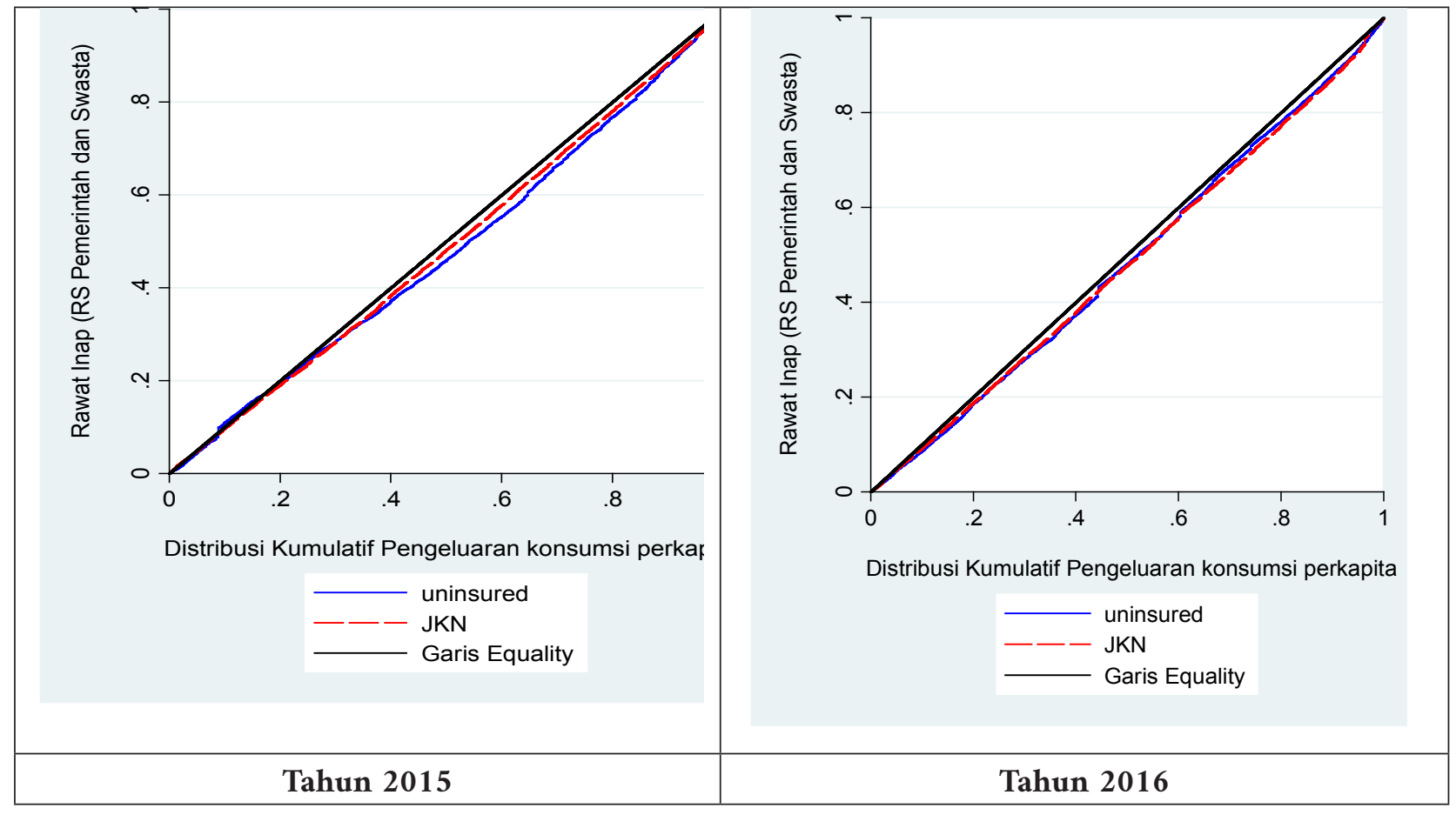

Tabel 3 Indeks Konsentrasi Layanan Rawat Inap di Rumah Sakit Berdasarkan Kepemilikan Jaminan Kesehatan Tahun 2015 dan Tahun 2016

\begin{tabular}{lccccc}
\hline \multirow{2}{*}{ Responden } & \multicolumn{2}{c}{2015} & \multicolumn{2}{c}{2016} & \multirow{2}{*}{$\begin{array}{c}\text { Selisih } \\
\text { CI }\end{array}$} \\
\cline { 2 - 5 } & CI & Std. Err. & CI & Std. Err. & CI \\
\hline JKN & 0.0288 & 0.0076 & 0.0375 & 0.0144 & 0.0086 \\
$\begin{array}{l}\text { Tidak ada } \\
\text { Jaminan }\end{array}$ & 0.0460 & 0.0172 & 0.0354 & 0.0097 & -0.0106 \\
\hline
\end{tabular}




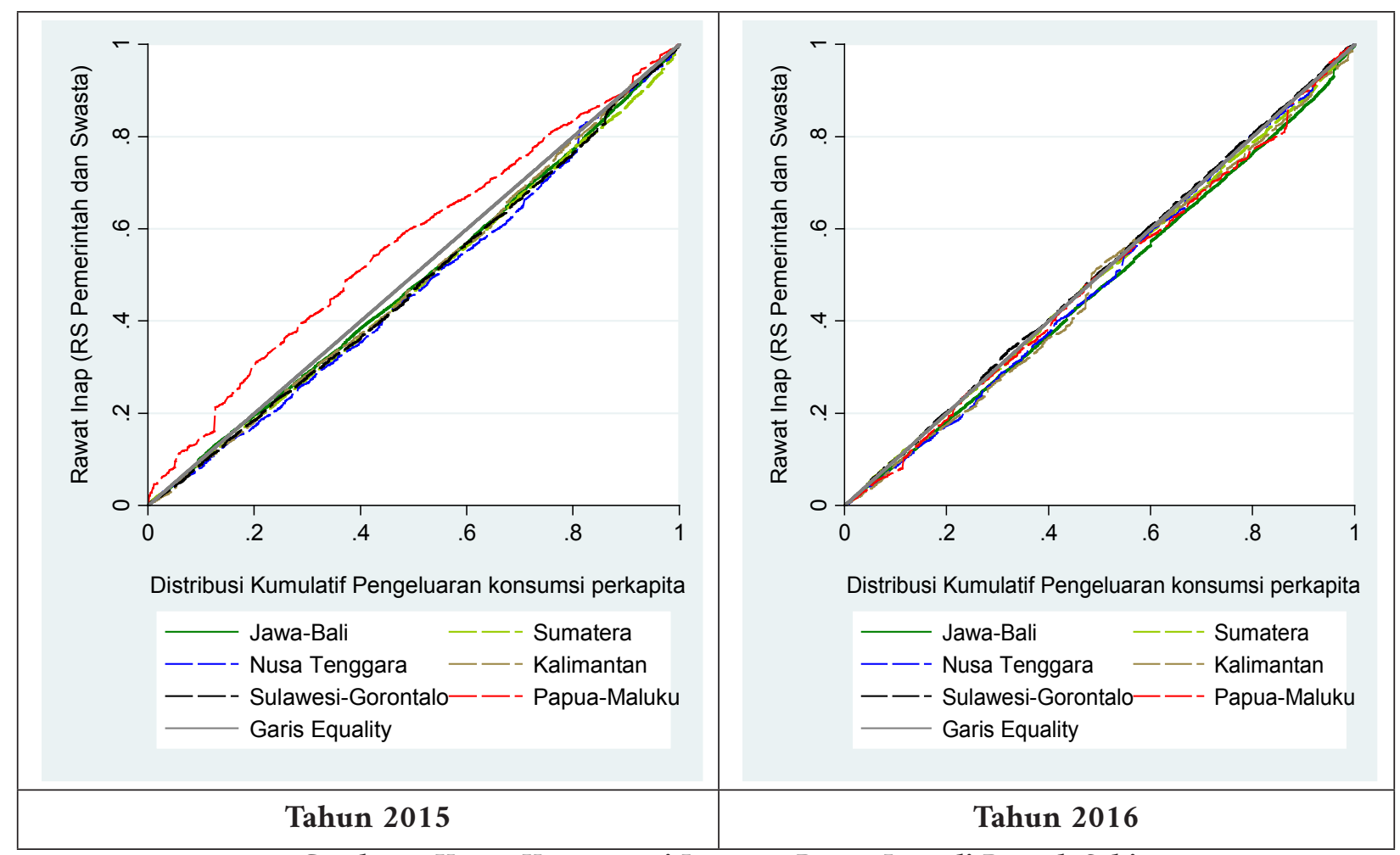

Gambar 3 Kurva Konsentrasi Layanan Rawat Inap di Rumah Sakit Berdasarkan Wilayah Regional Tahun 2015 dan Tahun 2016

Nilai positif pada indeks konsentrasi atau concentration index (CI) pada tahun 2015 dan 2016 menunjukkan bahwa utilisasi layanan rawat inap lebih banyak digunakan oleh kelompok kaya (pro rich) (Tabel 3). Dari nilai CI pada tahun 2015 dapat dilihat selisih yang cukup besar antara kelompok JKN (0.0288) dan kelompok yang tidak memiliki jaminan (0.0460) yaitu kelompok JKN memiliki ekuitas yang lebih baik (nilai CI lebih kecil) dibandingkan pada kelompok yang tidak memiliki jaminan.

Sedangkan pada tahun 2016 antara kelompok JKN (0.0375) dan kelompok yang tidak memiliki Jaminan (0.0354) memiliki nilai CI yang hampir sama, oleh karena itu kurva konsentrasi pada tahun 2016 terlihat hampir berhimpitan. Selain itu dapat dijelaskan pula bahwa pada kelompok peserta JKN terjadi peningkatan nilai CI sebesar 0.0086 yang artinya terjadi peningkatan inekuitas atau ketimpangan dalam utilisasi layanan rawat inap dari tahun 2015 ke 2016, walaupun jika diamati nilainya sangat kecil.

\section{Kurva Konsentrasi Layanan Rawat Inap berdasarkan Wilayah Regional}

Peneliti juga melakukan pengelompokkan responden berdasarkan regional wilayah tempat tinggal yang terdiri 6 regional wilayah yaitu: Regional
I (Jawa \& Bali), Regional II (Sumatera), Regional III (Nusa Tenggara), Regional IV (Kalimantan), Regional V (Sulawesi), Reginal VI (Papua/Maluku. Berdasarkan Gambar 3 pada regional VI tahun 2015 kurva konsentrasi tergambar di atas garis diagonal, artinya utilisasi layanan rawat inap pada regional VI banyak digunakan oleh masyarakat miskin. Hal tersebut juga diperkuat oleh nilai indeks konsentrasi pada tabel 4 yang bernilai negatif (-0.1298) artinya menunjukkan bahwa utilisasi layanan rawat inap rumah sakit lebih banyak digunakan oleh masyarakat miskin. Sedangkan untuk wilayah regional yang lain kurva konsentrasi berada dibawah garis diagonal dan nilai indeks konsentrasi bernilai positif, artinya bahwa utilisasi layanan rawat inap rumah sakit lebih banyak digunakan oleh masyarakat kaya.

Pada tahun 2016 berdasarkan gambar 3 menunjukkan adanya pergesaran kurva kearah semakin dekat dengan garis diagonal atau garis ekuitas, kurva masing-masing wilayah regional terlihat saling berhimpitan satu sama lain. Hal tersebut menunjukkan bahwa ekuitas antar wilayah regional semakin baik. Tabel 4 menjelaskan hasil perhitungan indeks konsentrasi (CI) berdasarkan wilayah regional. Pada tahun 2015 wilayah regional yang memiliki ketimpangan terkecil adalah wilayah 
Tabel 4 Indeks Konsentrasi Layanan Rawat Inap di Rumah Sakit Berdasarkan Wilayah Regional Tahun 2015 dan Tahun 2016

\begin{tabular}{cccccc}
\hline \multirow{2}{*}{ Responden } & \multicolumn{2}{c}{2015} & \multicolumn{2}{c}{2016} & \multirow{2}{*}{ Selisih CI } \\
\cline { 2 - 5 } & CI & Std. Err. & CI & Std. Err. & \\
\hline Regional I & 0.0319 & 0.0102 & 0.0518 & 0.0170 & 0.0199 \\
\hline Regional II & 0.0511 & 0.0160 & 0.0119 & 0.0116 & -0.0393 \\
\hline Regional III & 0.0590 & 0.0344 & 0.0295 & 0.0222 & -0.0295 \\
\hline Regional IV & 0.0350 & 0.0167 & 0.0381 & 0.0252 & 0.0031 \\
\hline Regional V & 0.0463 & 0.0171 & -0.0085 & 0.0125 & -0.0548 \\
\hline Regional VI & -0.1298 & 0.0517 & 0.0259 & 0.0424 & 0.1558 \\
\hline
\end{tabular}

\begin{tabular}{|c|c|c|c|c|c|c|c|c|}
\hline \multirow[b]{2}{*}{ Variabel } & \multicolumn{3}{|c|}{2015} & \multicolumn{5}{|c|}{2016} \\
\hline & Elastisitas & $\mathrm{CI}$ & Kontribusi & $\begin{array}{c}\% \\
\text { Kontribusi }\end{array}$ & Elastisitas & $\mathrm{CI}$ & Kontribusi & $\begin{array}{c}\% \\
\text { Kontribusi }\end{array}$ \\
\hline \multicolumn{9}{|l|}{ Umur : } \\
\hline 5-14 tahun & 0.002 & -0.067 & -0.000 & $-0.44 \%$ & 0.006 & -0.026 & -0.000 & $-0.42 \%$ \\
\hline 15-24 tahun & 0.009 & 0.006 & 0.000 & $0.14 \%$ & 0.014 & -0.009 & -0.000 & $-0.35 \%$ \\
\hline 25-64 tahun & 0.206 & 0.027 & 0.006 & $16.49 \%$ & 0.218 & 0.020 & 0.004 & $11.19 \%$ \\
\hline$>65$ tahun & 0.058 & 0.012 & 0.001 & $2.07 \%$ & 0.051 & -0.004 & -0.000 & $-0.48 \%$ \\
\hline $\begin{array}{l}\text { Jenis Kelamin } \\
\text { : laki-laki }\end{array}$ & 0.092 & -0.017 & -0.002 & $-4.61 \%$ & 0.089 & -0.007 & -0.001 & $-1.69 \%$ \\
\hline Pendapatan & 1.459 & 0.029 & 0.042 & $124.29 \%$ & 1.742 & 0.029 & 0.050 & $130.40 \%$ \\
\hline $\begin{array}{l}\text { Lokasi } \\
\text { Tempat } \\
\text { Tinggal : Kota }\end{array}$ & -0.019 & 0.107 & -0.002 & $-5.93 \%$ & 0.022 & 0.123 & 0.003 & $6.96 \%$ \\
\hline $\begin{array}{l}\text { Status } \\
\text { Pernikahan : } \\
\text { menikah }\end{array}$ & -0.061 & 0.007 & -0.000 & $-1.35 \%$ & -0.051 & -0.008 & 0.000 & $1.13 \%$ \\
\hline $\begin{array}{l}\text { Pekerjaan : } \\
\text { bekerja }\end{array}$ & -0.067 & 0.040 & -0.003 & $-7.89 \%$ & -0.076 & 0.048 & -0.004 & $-9.65 \%$ \\
\hline \multicolumn{9}{|l|}{ Pendidikan : } \\
\hline SD & 0.019 & -0.088 & -0.002 & $-4.99 \%$ & -0.002 & -0.053 & 0.000 & $0.30 \%$ \\
\hline SMP & 0.005 & 0.002 & 0.000 & $0.03 \%$ & -0.004 & -0.007 & 0.000 & $0.08 \%$ \\
\hline SMA & -0.003 & 0.220 & -0.001 & $-2.17 \%$ & -0.012 & 0.139 & -0.002 & $-4.24 \%$ \\
\hline D1-S3 & -0.005 & 0.506 & -0.003 & $-7.91 \%$ & -0.015 & 0.521 & -0.008 & $-21.07 \%$ \\
\hline \multicolumn{9}{|l|}{ Regional : } \\
\hline Regional 2 & 0.008 & 0.005 & 0.000 & $0.12 \%$ & 0.006 & 0.018 & 0.000 & $0.29 \%$ \\
\hline Regional 3 & 0.001 & -0.272 & -0.000 & $-0.60 \%$ & 0.000 & -0.255 & 0.000 & $0.05 \%$ \\
\hline Regional 4 & -0.003 & 0.166 & -0.000 & $-1.38 \%$ & 0.003 & 0.137 & 0.000 & $1.16 \%$ \\
\hline Regional 5 & 0.010 & -0.125 & -0.001 & $-3.87 \%$ & 0.008 & -0.072 & -0.001 & $-1.49 \%$ \\
\hline Regional 6 & 0.002 & 0.121 & 0.000 & $0.84 \%$ & 0.004 & 0.109 & 0.000 & $1.11 \%$ \\
\hline JKN & 0.076 & 0.002 & 0.000 & $0.46 \%$ & 0.114 & 0.010 & 0.001 & $3.04 \%$ \\
\hline Residual & & & -0.001 & $-3.30 \%$ & & & -0.006 & $-16.30 \%$ \\
\hline Total & & & 0.034 & $100.00 \%$ & & & 0.038 & $100.00 \%$ \\
\hline
\end{tabular}


regional I dengan nilai indeks konsentrasi 0.0319 , sedangkan pada tahun 2016 wilayah regional yang memiliki ketimpangan terkecil adalah wilayah regional II yakni wilayah Sumatera dengan nilai CI sebesar 0.0119. Sebagian besar wilayah regional memiliki nilai indeks konsentrasi yang cenderung menurun dari tahun 2015 ke 2016 seperti pada regional II, III dan V. Semakin kecil nilai indeks konsentrasi maka semakin mendekati ekuitas dan semakin kecil ketimpangan dalam utilisasi layanan rawat inap di rumah sakit. Sedangkan untuk wilayah regional I, IV dan VI pada tahun 2016 nilai indeks konsentrasinya meningkat, namun peningkatan nilainya kecil. Artinya pada wilayah regional I, IV dan VI terjadi peningkatan ketimpangan dalam utilisasi layanan rawat inap rumah sakit.

\section{Dekomposisi Indeks Konsentrasi}

Untuk melihat kontribusi masing-masing variabel karakterisktik individu dalam penelitian terhadap ekuitas layanan rawat inap di rumah sakit dilakukan dengan menggunakan analisis dekomposisi indeks konsentrasi. Kontribusi yang bernilai positif artinya variabel karakteristik individu menambah ketimpangan atau inekuitas dalam utilisasi layanan rawat inap. Dan sebaliknya kontribusi yang bernilai negatif artinya variabel karakteristik individu mengurangi ketimpangan dalam utilisasi layanan rawat inap.

Dari tabel 4 menunjukkan bahwa ketidaksetaraan atau inekuitas utilisasi layanan rawat inap yang pro kaya disebabkan oleh ketidaksetaraan umur, pendapatan, jenjang pendidikan, wilayah regional tempat tinggal serta kepemilikan JKN. Sedangkan variabel jenis kelamin dan pekerjaan mengurangi inekuitas dalam utilisasi layanan rawat inap di rumah sakit pada tahun 2015 dan 2016. Untuk variabel letak tempat tinggal di perkotaan dan status menikah mengurangi inekuitas dalam utilisasi layanan rawat inap di rumah sakit pada tahun 2015, sedangkan pada tahun 2016 bernilai positif artinya menambah inekuitas dalam utilisasi layanan rawat inap di rumah sakit.

Dari seluruh variabel independen, pendapatan memiliki kontribusi terbesar yang menyebabkan tingkat ketimpangan utilisasi layanan rawat inap tahun 2015 dan 2016 yaitu sebesar 124,29\% pada tahun 2015 dan 130,40\% pada tahun 2016 . Elastisitas variabel pendapatan juga bernilai positif artinya semakin tinggi pendapatan akan semakin tinggi pemanfaatan terhadap pelayanan kesehatan.

Kontribusi variabel kepemilikan JKN terhadap tingkat ketimpangan utilisasi rawat inap menunjukkan nilai positif baik pada tahun 2015 maupun tahun 2016 yaitu sebesar (0.000) pada tahun 2015 dan sebesar (0.001) pada tahun 2016. Hal tersebut mengindikasikan bahwa dengan kepemilikan JKN justru menambah ketimpangan atau inekuitas pada layanan rawat inap di rumah sakit. Kontribusi kepemilikan JKN terhadap inekuitas sangat kecil yaitu sebesar $0,46 \%$ pada tahun 2015 dan sebesar 3,04\% pada tahun 2016 .

\section{Pembahasan}

Program Jaminan Kesehatan Nasional secara umum bertujuan untuk mempermudah masyarakat untuk mengakses layanan kesehatan dan mendapatkan pelayanan kesehatan yang bermutu. Kepemilikan asuransi kesehatan berhubungan positif dengan akses ke sarana pelayanan kesehatan (Januarizal, 2008). Menurut Hidayat (2010) program asuransi kesehatan sosial dapat meningkatkan kunjungan masyarakat ke pelayanan kesehatan, dengan efek tertinggi pada kelompok miskin. Begitu juga dengan penelitian Sparrow (2010) tentang adanya askeskin di Indonesia membuktikan bahwa ada peningkatan rawat jalan pada kelompok miskin. Hal ini sesuai dengan hasil penelitian ini yang menunjukkan bahwa utiliasasi layanan rawat inap yang terus meningkat.

Penelitian Zhou Z, et al. (2011) menemukan bahwa dengan kebutuhan yang sama untuk layanan rawat inap, individu yang lebih kaya menggunakan lebih banyak layanan rawat inap daripada individu yang lebih miskin. Penelitian yang dilakukan Flato dan Zhang (2016) menemukan hal serupa yakni kelompok kaya lebih banyak menggunakan rumah sakit daripada kelompok kurang mampu. Di Indonesia, penelitian Oktavianti (2017) menunjukkan bahwa penduduk kaya di Indonesia lebih banyak memanfaatkan pelayanan rumah sakit dibandingkan dengan penduduk miskin. Hal tersebut sejalan dengan hasil penelitian ini, bahwa berdasarkan kurva konsentrasi dan indeks konsentrasi pada tahun 2015 dan 2016 menunjukkan bahwa utilisasi layanan rawat inap lebih banyak digunakan oleh kelompok kaya (pro rich).

Kondisi yang equity dalam utilisasi layanan kesehatan bagi semua penduduk merupakan kondisi yang ideal yang diharapkan oleh semua negara. Penelitian Nugraheni (2017) dengan menggunakan 
data panel IFLS 2007 dan 2014 menunjukkan bahwa program JKN meningkatkan akses layanan rawat inap $115,8 \%$ dan terbukti mampu mempersempit kesenjangan layanan rawat inap di rumah sakit diantara peserta JKN.

Sementara Flato dan Zhang (2016) melakukan penelitian mengenai inequity utilisasi pelayanan kesehatan sebelum dan sesudah universal health coverage (UHC). Hasil penelitiannya menunjukkan bahwa inequity tingkat utilisasi layanan kesehatan meningkat setelah adanya kebijakan UHC. Penelitian Flato dan Zhang (2016) tersebut sejalan dengan penelitian ini yang menemukan bahwa pada tahun kedua dan ketiga pelaksanaan JKN terjadi peningkatan inekuitas utilisasi layanan rawat inap dengan peningkatan nilai indeks konsentrasi yang sangat kecil yaitu 0.0045 .

\section{Variabel Independen yang mempengaruhi ekuitas}

Variabel pendidikan memberikan kontribusi negatif terhadap kesenjangan utilisasi layanan rawat inap di rumah sakit. Variabel pendidikan SMA dan D1-S3 memiliki kontribusi yang negatif terhadap kesenjangan yaitu sebesar 7,91\% (tahun 2015) dan sebesar 21,07\% (tahun 2016). Artinya semakin tinggi pendidikan seseorang maka akan mengurangi kesenjangan atau inekuitas dalam utilisasi layanan rawat inap di rumah sakit. Pendidikan yang tinggi memungkinkan seseorang untuk lebih dini dalam mengenali gejala suatu penyakit, sehingga memungkinkan untuk segera mencari pengobatan atau pelayanan kesehatan (Tampi et al, 2016).

Dari seluruh variabel independen, pendapatan memiliki kontribusi terbesar yang menyebabkan tingkat ketimpangan utilisasi layanan rawat inap yaitu 124,29\% tahun 2015 dan 130,40\% pada 2016 . Elastisitas variabel pendapatan juga bernilai positif yang artinya semakin tinggai pendapatan akan semakin tinggi pemanfaatan terhadap pelayanan kesehatan. Hal tersebut sesuai dengan penelitian Zhou Z, et al. (2011) serta Flato dan Zhang (2016) menemukan bahwa kelompok kaya lebih banyak menggunakan rumah sakit daripada kelompok kurang mampu.

Variabel kepesertaan JKN memiliki kontribusi yang positif terhadap ketimpangan utilisasi rawap inap yaitu sebesar 0.000 (tahun 2015) dan sebesar 0.001 (tahun 2016). Hal ini mengindikasikan bahwa dengan kepemilikan JKN menambah ketimpangan atau inekuitas pada layanan rawat inap di rumah sakit. Kontribusi kepemilikan JKN terhadap inekuitas sangat kecil yaitu sebesar 0,46\% (tahun 2015) dan sebesar 3,04\% (tahun 2016). Hasil penelitian ini sejalan dengan penelitian Flato dan Zhang (2016) yang menunjukkan bahwa inequity tingkat utilisasi layanan kesehatan meningkat setelah adanya kebijakan UHC.

Peningkatan ketimpangan pada peserta JKN salah satunya dipengaruhi oleh ketidakseimbangan peningkatan jumlah peserta JKN dengan peningkatan jumlah fasilitas yang bekerjasama dengan BPJS Kesehatan. Berdasarkan profil kesehatan 2016 proporsi jumlah RS Swasta (43,17\%) yang berkerjasama dengan BPJS Kesehatan lebih banyak dibandingkan dengan RS Pemerintah (32,87\%). Padahal kenyataan yang terjadi dilapangan kita tahu bahwa di RS Swasta masih terdapat pembatasan penerimaan pasien BPJS Kesehatan, sehingga ada banyak pasien yang ditolak rujukannya karena keterbatasan tempat rawat inap. Idealnya program JKN dapat memperbaiki ekuitas dalam utilisasi layanan kesehatan, untuk itu perlu dilakukan evaluasi dan monitoring program JKN secara rutin dan berkala agar program JKN tetap dapat berjalan dan berkelanjutan hingga mencapai cakupan semesta.

Berdasarkan Profil Kesehatan Indonesia Tahun 2015 dan 2016 jumlah Fasilitas Kesehatan Rujukan Tingkat Lanjutan (FKRTL) yang bekerjasama dengan BPJS Kesehatan meningkat dari 1.847 menjadi 2069 FKRTL. Dengan peningkatan jumlah FKRTL yang bekerjasama dengan BPJS Kesehatan tersebut diharapkan peserta JKN dapat memperoleh perbaikan akses pelayanan pada fasilitas kesehatan dengan lebih baik dan lebih berkualitas, sehingga dapat memperkecil ketimpangan dalam pemanfaatan layanan kesehatan rawat inap. Namun kenyataannya peningkatan jumlah tersebut belum cukup memenuhi kebutuhan akan layanan kesehatan bagi masyarakat yang membutuhkan. Terbukti dalam penelitian ini masih terjadi peningkatan ketimpangan atau inekuitas dalam utilisasai layanan rawat inap. Peningkatan akses pelayanan kesehatan sebaiknya diimbangi juga dengan peningkatan supply side seperti ketersediaan tenaga kesehatan dan fasilitas pelayanan kesehatan yang memadai di semua wilayah. Menurut Nadjib (1999) salah satu faktor penting dalam mewujudkan ekuitas dalam pelayanan kesehatan adalah adanya sarana pelayanan kesehatan.

Diharapkan pemerintah dapat menambah jumlah fasilitas kesehatan melalui pembangunan sarana- 
prasarana fasilitas kesehatan yang baru dengan bekerja sama dengan berbagai pihak, baik pihak pemerintah daerah maupun pihak swasta melalui mekanisme kerjasama atau semacamnya agar dapat memenuhi kebutuhan masyarakat yang memadai akan fasilitas kesehatan terutama didaerah yang inekuitas atau ketimpangannya meningkat seperti Jawa/Bali dan Kalimantan. Selain itu, pihak BPJS sebagai pengelola JKN diharapkan untuk dapat lebih memperluas area kerjasama dengan Fasilitas Kesehatan milik swasta baik itu swasta nasional maupun swasta asing agar dapat menerima pasien BPJS. Menciptakan suatu mekanisme kebijakan pembayaran yang lebih pro terhadap Fasilitas Kesehatan agar lebih tertarik untuk dapat bergabung dengan program JKN agar dapat melayani pasien peserta JKN.

\section{Kesimpulan dan Saran}

\section{Kesimpulan}

Terjadi peningkatan ketidaksetaraan atau inekuitas utilisasi layanan rawat inap di rumah sakit pada tahun 2015 ke tahun 2016 yang dilihat dari selisih nilai indeks konsentrasi sebesar 0.0045. Ketidaksetaraan atau inekuitas utilisasi layanan rawat inap di rumah sakit yang pro kaya disebabkan oleh ketidaksetaraan umur, pendapatan, jenjang pendidikan, wilayah regional tempat tinggal serta kepemilikan JKN. Sedangkan variabel jenis kelamin dan pekerjaan mengurangi ketidaksetaraan atau inekuitas dalam utilisasi layanan rawat inap di rumah sakit pada tahun 2015 dan 2016.

\section{Saran}

Diharapkan pemerintah dapat menambah jumlah fasilitas kesehatan melalui pembangunan sarana dan prasarana fasilitas kesehatan dengan bekerjasama dengan berbagai pihak, baik pihak pemerintah daerah maupun pihak swasta melalui mekanisme kerjasama atau semacamnya agar dapat memenuhi kebutuhan masyarakat yang memadai akan fasilitas kesehatan terutama didaerah yang inekuitas atau ketimpangannya meningkat sesuai hasil dalam penelitian ini seperti Jawa/Bali dan Kalimantan. Bagi BPJS Kesehatan agar tercapai keberlangsungan program JKN, perlu digalakan kembali sosialisasi untuk menjaring kepesertaan JKN dan yang terpenting sosialisasi agar masyarakat terutama yang membayar iuran secara mandiri untuk terus mempertahankan kepesertaannya. Melakukan perbaikan dan inovasi pada aplikasi mobile JKN seperti menambah fitur untuk melihat ketersediaan ruang rawat inap pada rumah sakit agar peserta dapat dengan mudah memperoleh informasi sebelum dirujuk dari FKTP serta penambahan fitur pendaftaran pelayanan secara online untuk menghindari penumpukan antrian di rumah sakit. Pihak BPJS Kesehatan sebagai pengelola JKN diharapkan untuk dapat lebih memperluas area kerjasama dengan Fasilitas Kesehatan milik swasta baik itu swasta nasional maupun swasta asing agar dapat menerima pasien BPJS dengan menciptakan suatu mekanisme kebijakan pembayaran yang lebih pro terhadap Fasilitas Kesehatan agar lebih tertarik untuk dapat bergabung dengan program JKN agar dapat melayani pasien peserta JKN. Bagi peneliti selanjutnya perlu dilakukan analisis evaluasi dampak program JKN untuk melihat peningkatan capaian perbaikan akses dan ekuitas guna mencapai tujuan utama program JKN.

\section{Daftar Pustaka}

BPS. 2016. Indonesia- Survei Sosial Ekonomi Nasional 2016 Maret (Modul).Flatø H, Zhang H. 2016. Inequity in level of healthcare utilization before and after universal health coverage reforms in China: evidence from household surveys in Sichuan Province. Int J Equity Health. 15:96.

Hidayat, Budi. 2010. Bukti Empiris Kebijakan Asuransi Kesehatan Sosial: Analisis Data Survey Aspek Kehidupan Rumah Tangga Indonesia (Sakerti). Jurnal Manajemen Pelayanan Kesehatan Vol.13. 117-225.

Januarizal. 2008. Hubungan Kepemilikan Asuransi dengan Pemanfaatan Sarana Pelayanan Kesehatan di Provinsi Jambi (Analisis Data Susenas 2006). Tesis: Universitas Indonesia.

Kementerian Kesehatan RI. 2015. Profil Kesehatan Indonesia 2014. Jakarta, Kemkes RI

Kementerian Kesehatan RI. 2016. Profil Kesehatan Indonesia 2015. Jakarta, Kemkes RI

Kementerian Kesehatan RI. 2017. Profil Kesehatan Indonesia 2016. Jakarta, Kemkes RI

Nadjib, M. 1999. Pemerataan akses pelayanan rawat jalan di berbagai wilayah Indonesia. Desertasi: Universitas Indonesia.

Nugraheni, Wahyu Pudji. 2017. Dampak Program Jaminan Kesehatan Nasional Terhadap Ekuitas Akses Layanan Rawat Inap Rumah Sakit. Desertasi: Universitas Indonesia

Oktavianti, Yessi. 2017. Analisis Ekuitas Utilisasi Pelayanan Rumah Sakit pada Implementasi Awal 
Program JKN di Indonesia Tahun 2014 (Susenas 2014). Tesis: Universitas Indonesia

O’Donnell, Eddy Van Doorslaer, Adam Wagstaff, Magnus Lindelow. 2008. Analyzing Health Equity using Household Survey Data: A Guide to Techniques and their Implementation, World Bank Publications, The World Bank, number 6896

Republik Indonesia. 2004. Undang-Undang Nomor 40 tentang Sistem Jaminan Sosial Nasional.

Republik Indonesia. 2009. Undang-Undang Republik Indonesia Nomor 36 Tentang Kesehatan.

Rolindrawan, Djoni. 2015. The Impact of BPJS Health Implementation for the Poor and Near Poor on the Use of Health Facility. 2015. Procedia - Social and Behavioral Sciences 211: 550 - 559

Tampi J, Rumayar A A, Tucunan A A T. 2016. Hubungan antara pendidikan, pendapatan dan pekerjaan dengan pemanfaatan pelayana kesehatan di rumah sakit umum darah Menembo-Nembo Bitung 2015. KESMAS Jurnal Kesehatan Masyarakat Universitas Sam Ratulangi. 5(1)

Tarigan, Ingan \& Suryati, Taty. 2018. Gambaran Out of Pocket pada Awal Era JKN di Indonesia. Jurnal Penelitian dan Pengembangan Pelayanan Kesehatan. 1(2):141-146.

Zhou Z, Gao J, Fox A, Rao K, Xu K, Xu L, et al. 2011. Measuring the equity of inpatient utilization in Chinese rural areas. BMC Health Serv Res. 11 (1):201. Wagstaff A, van Doorslaer E, Watanabe N. 2003. On Decomposing the Causes of Health Sector Inequalities, with an Application to Malnutrition Inequalities in Vietnam. Journal of Econometrics $112(1): 219-227$. 